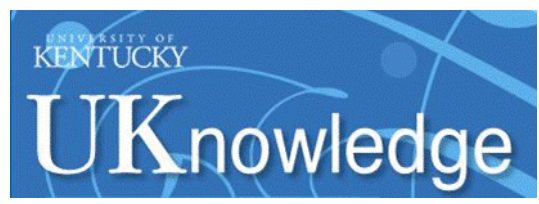

University of Kentucky

UKnowledge

$11-2019$

\title{
Smart Plug and Circuit Breaker Technologies for Residential Buildings in the US
}

\author{
Rosemary E. Alden \\ University of Kentucky, rosemary.alden@uky.edu \\ Peng Han \\ University of Kentucky, peng.han@uky.edu \\ Dan M. Ionel \\ University of Kentucky, dan.ionel@uky.edu
}

Follow this and additional works at: https://uknowledge.uky.edu/peik_facpub

Part of the Power and Energy Commons

Right click to open a feedback form in a new tab to let us know how this document benefits you.

\section{Repository Citation}

Alden, Rosemary E.; Han, Peng; and Ionel, Dan M., "Smart Plug and Circuit Breaker Technologies for Residential Buildings in the US" (2019). Power and Energy Institute of Kentucky Faculty Publications. 9. https://uknowledge.uky.edu/peik_facpub/9

This Conference Proceeding is brought to you for free and open access by the Power and Energy Institute of Kentucky at UKnowledge. It has been accepted for inclusion in Power and Energy Institute of Kentucky Faculty Publications by an authorized administrator of UKnowledge. For more information, please contact UKnowledge@lsv.uky.edu. 


\title{
Smart Plug and Circuit Breaker Technologies for Residential Buildings in the US
}

\author{
Digital Object Identifier (DOI)
}

https://doi.org/10.1109/ICRERA47325.2019.8996877

\section{Notes/Citation Information \\ Published in 2019 8th International Conference on Renewable Energy Research and Applications (ICRERA).}

(c) 2019 IEEE Copyright Notice. "Personal use of this material is permitted. Permission from IEEE must be obtained for all other uses, in any current or future media, including reprinting/republishing this material for advertising or promotional purposes, creating new collective works, for resale or redistribution to servers or lists, or reuse of any copyrighted component of this work in other works."

The document available for download is the authors' manuscript version that is accepted for publication. The final published version is copyrighted by IEEE and available as: R. E. Alden, P. Han, and D. M. Ionel, "Smart Plug and CircuitBreaker Technologies for Residential Buildings in the US," 8th International Conference on Renewable Energy Research and Applications (ICRERA), Brasov, Romania, Nov. 3-6,2019, pp. 1018-1021, doi: 10.1109/ICRERA47325.2019.8996877. 


\title{
Smart Plug and Circuit Breaker Technologies for Residential Buildings in the US
}

\author{
Rosemary E. Alden, Student Member, IEEE, Peng Han, Member, IEEE, and Dan M. Ionel, Fellow, IEEE \\ SPARK Laboratory, Department of Electrical and Computer Engineering, \\ University of Kentucky, Lexington, KY, USA \\ rosemary.alden@uky.edu, peng.han@uky.edu,dan.ionel@ieee.org
}

\begin{abstract}
A significant proportion of the total energy in conventional homes across the United States is used by electric plug loads, which include various electronic devices and home appliances, excluding the heating, ventilation and air conditioning (HVAC) units and electric water heaters. Considerable energy savings are expected to be possible by managing these plug loads effectively based on user behavior data. Smart plugs and circuit breakers that can control and monitor energy usage on a real-time basis are becoming increasingly popular alongside the rapid development of smart home energy management. This paper reviews the recent advances on the subject matter with emphasis on the feasibility of energy monitoring and the flexibility of system integration. A relatively low cost laboratory implementation, using a general-purpose single-board computer, which was designed, built, and tested in order to provide enhanced power quality monitoring capabilities and to support research in this fast growing area, is described together with experimental sample results.
\end{abstract}

Index Terms-Energy savings, monitoring, plug load, smart circuit breaker, smart home, smart plug.

\section{INTRODUCTION}

Smart home technologies have been drawing more attention in recent years for energy conservation in households globally [1]-[3]. A smart home is defined as a residence equipped with communications network, linking sensors, and domestic devices and appliances that can be remotely monitored, accessed or controlled, and which provides services that respond to the needs of its inhabitants [4]. The smart home energy management system (HEMS) will be incorporated to provide energy management services in order to efficiently monitor and manage electricity generation, storage, and consumption in smart homes.

There are five major end uses in U.S. households, i.e., space heating, water heating, air conditioning, refrigerators and others, which include electronics, lighting and other appliances. Electric water heaters and heating, ventilation and air conditioning (HVAC) units are not included in other appliances. According to the survey data from 2015 residential energy consumption survey (RECS) by the U.S. Energy Information Administration (EIA), the energy used by other appliances, electronics and lighting accounts for $26.2 \%$ of the total electricity consumption [5]. In the South and West, the proportion of this end use type is higher ( $31.1 \%$ for both) than that in the Northeast and Midwest. The detailed energy consumption breakdown in conventional homes is illustrated in Fig. 1. The high proportion of other appliances, electronics and lighting load promises considerable energy savings if they can be managed efficiently [6], [7]. New technologies such as the smart plugs and circuit breakers are bringing the capability of energy monitoring to the consumer in hopes of achieving these energy savings [8].

The turning on/off of home appliances, electronics and lighting heavily depends on customer behaviors. To achieve effective power conservation in this type of end use, electric power companies would like to have enough knowledge about users' behavior, i.e., how people consume their electricity [9]. At the same time, users themselves also need to be aware of their power consumption habits. Smart plugs and circuit breakers, therefore, have been proposed to monitor and optimize electric power usage in homes. The collected power consumption data can then be analyzed to measure the power usage and power quality, e.g., power factor and total harmonic distortion (THD), as well as linked to human behaviors for optimal scheduling. They can also be connected to smart HEMS, e.g., the building energy management open source software (BEMOSS) [10], and accessed through human-machine interfaces.

Smart plugs and circuit breakers make it possible to turn on/off and control electrical devices from anywhere. This allows one to monitor the home energy usage from a smart phone, tablet or virtual digital assistants. By using smart plugs and circuit breakers, one can convert a conventional home into a smart home to control the usage of electrical appliances that are plugged into them and thus control the energy consumption.

In this paper, we review the recent advancements in smart home and HEMS, with an emphasis on smart plug and circuit breaker technologies, and introduce the design practice of a portable smart plug device, which was implemented in the SPARK Laboratory at University of Kentucky using widely available hardware and open source software. The new smart plug has relatively low cost and the enhanced ability to measure instantaneous power usage and quality. This device can be directly connected to existing home controllers and become part of the HEMS. Test results are provided and compared with those obtained from an integrated circuit (IC) energy monitoring demonstration board and from measurement instrumentation. 


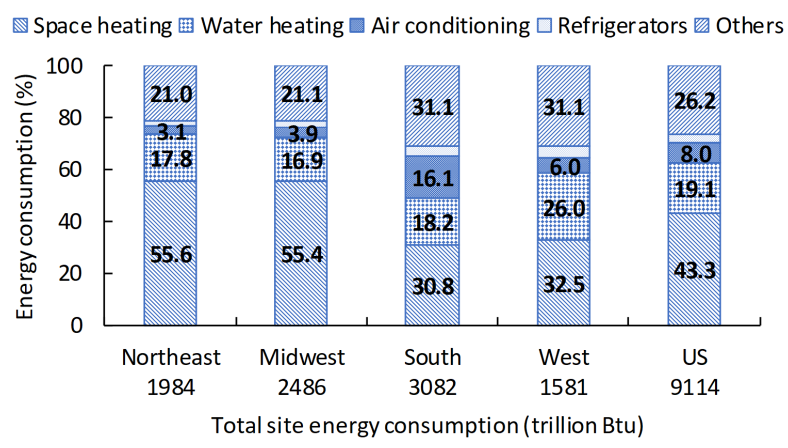

Figure 1. Total end-use consumption in the Northeast, Midwest, South, West and U.S. based on the data provided by 2015 RECS. Refrigerators consume the lowest fraction compared to other end uses so the percentage is not shown.

\section{SMART HOMES AND HEMS}

The HEMS consists of a centralized controller, which communicates with all the renewable energy generators, energy storages and end-use loads, as illustrated in Fig. 2. The realtime electricity consumption data from in-home appliances, including schedulable and nonschedulable appliances, will be collected by smart plugs and/or circuit breakers to implement optimal demand dispatch [11], [12]. In addition, the smart meter can be used as the interface between power utilities and the smart houses [13]. The smart meter receives demand response signals from the power utility as an input to the HEMS, and the optimization of home appliance scheduling can be implemented for the residential demand response.

Smart homes promise efficient energy consumption, improved quality of life, security and safety for consumers, as well as opportunities of growth for the electric utility industry, home appliance manufacturers and smart-home platform providers [12]. The construction and conversion of conventional homes into smart homes are important endeavors to bring the smart home from concept to reality and have seen a tremendous increase lately, which can be attributed to the advancements in enabling technologies, including the internet of things (IoT) [14], machine learning, artificial intelligence, big data analytics [15] and smart devices, etc.

\section{IC-BASEd ENERGy MEtering AND MONitoring}

The remote control capabilities of a HEMS can be achieved by radio frequency (RF) switches and a controller with an RF transmitter. The energy monitoring function requires additional sensors, analog-to-digital converters (ADCs) and microcontrollers. Most popular smart plug and circuit breaker products nowadays are based on energy-metering ICs. Example ICs are MCP390xx [16], ADE9000 [17] and MSP430F67xx family of devices. They can be used to measure active power for single-phase or multi-phase systems. Evaluation boards based on these IC devices are also available to test a variety of customized meter designs [18], [19].

Typical IC-based commercial implementations are the Monoprice wireless smart plug wall outlet and Kasa smart WiFi power outlet. The wireless smart plug wall outlets provide the remote monitoring and control of home appliances directly

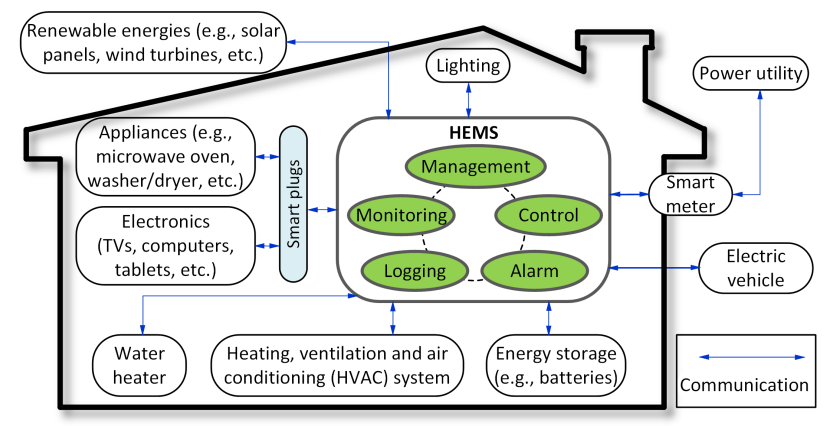

Figure 2. Schematics for a typical smart home incorporating HEMS and smart plugs with the main objective of reducing energy usage. The HEMS performs management, monitoring, control, logging and alarm functions.

from the Android or iOS smart phone or tablet. The application for phones and tablets allows for multiple device connections from all rooms of a home. This provides the users the ability to customize the control settings to make there own HEMS conveniently through the graphical user interface (GUI) of the app. Smart circuit breakers developed by Sense use similar IC-based technology [20].

Individual smart plugs are relatively low cost plug-andplay solutions to home energy savings, but the benefits are limited to one plug at a time. A number of electrical equipment manufacturers, such as Leviton Manufacturing Company, Inc. and startups Sense and PlutonPower focus on smart circuit breakers, which integrating two main smart functions, i.e., remote control and energy monitoring, directly into individual circuit breakers, giving homeowners more flexibility and information on the power management in their homes [21]. With such smart circuit breakers, homeowners will be able to track power consumption on a per-appliance or branch circuit basis, get alerts when circuit breakers trip and the reason behind, or remotely shut off circuit breakers from apps.

The application of smart circuit breakers into power distribution management has been promoted by Eaton Corporation, Inc. and Schneider Electric, which gives electrical equipment the ability to directly communicate with people and gather the power information in real time [22], [23]. They can be used to monitor and control a single breaker or an entire low-voltage electrical distribution system in different locations around the globe. Energy information as well as physical properties including trip status, cycle count, and contact wear indicators, etc., can be obtained to improve utility service and optimize the grid by supporting demand response, distributed energy resources, solar installation monitoring, energy storage, EV charging and energy management. The advancements in smart circuit breakers also accelerate the ongoing development of digital circuit breakers, which tend to be faster, safer and more reliable due to the absence of mechanical parts.

\section{Research Laboratory DeVElopment USing A General-PURPose Single-BOARD COMPUTER}

The developed smart plug has improved capabilities. It can not only switch on/off the plug-in device, but can also monitor the power consumption and quality. The new smart 
plug includes electronic communication capabilities and can be further developed to be connected to an HEMS for human behavior analysis and optimization of home energy usage. The schematic diagram of the designed smart plug and the prototype are shown in Fig. 3a and Fig. 3b, respectively.

\section{A. System Configuration}

The designed smart plug consists of a Hall effect current transformer LTS 25-NP and a voltage transducer ZMPT101B in order to measure the $\mathrm{AC}$ current and voltage. A $5 \mathrm{~V}$ relay, designed for Raspberry $\mathrm{Pi}$, controls power through the smart plug for use with a HEMS. An Arduino Uno receives analog signals from the sensors and a digital signal from the relay; then, it sends the collected data via serial connection to a Raspberry $\mathrm{Pi} 3 \mathrm{~B}+$. The communication is done by an RS-485 serial connection at a 115200 baud rate. Upon receiving this signal, the Raspberry Pi operates as the potential core for a HEMS or as a storage device for the instantaneous current and voltage readings through its Linux open source operating system and Python3.

\section{B. Data Collecting and Processing}

The Arduino Uno utilizes $\mathrm{C}++$ in an integrated development environment (IDE) to collect instantaneous measurements from the voltage transducer and current transformer. These initially provide an analog signal that must be converted by the Arduino Uno's internal ADC. The voltage waveform is measured first then the current waveform through a series of for-loops. This is a byproduct of a hardware limitation of one ADC and the 10-bit resolution in the Arduino Uno.

The designed smart plug has a measuring frequency of 8,333 $\mathrm{Hz}$, and thus, a sampling rate of $120 \mathrm{~ms}$. This allows for the capture of 140 data points of voltage and current over one cycle and for a rather detailed representation of the waveforms. The instantaneous measurements can be fed into a HEMS run by the Raspberry Pi or stored. For further detailed power quality analysis in MATLAB with fast Fourier transformation (FFT), the test data is stored in a csv file and synchronized over one cycle.

\section{Experiments}

Tests were performed on a variety of typical residential appliances and laboratory equipment, including a coffee maker, a hair dryer, a vacuum cleaner and a TekPower DC power supply. The power quality parameters, i.e., power factor and THD, are calculated and reported in Table I. The voltage and current waveforms are shown in Fig. 4.

The coffee maker is a resistive load, so it has a unit power factor and the minimum THD, as shown in Table I. Inside the hair dryer under test are a universal motor-driven fan and a heating element. The voltage and current waveforms of the hair dryer are shown in Fig. 4a. The current is in phase with the voltage and the harmonic distortions are very low. The vacuum cleaner is a nonlinear load and there are 3rd and 5th harmonics in the current waveform, as shown in Fig. 4b. The THD is $19.6 \%$ when the vacuum cleaner is operated at full

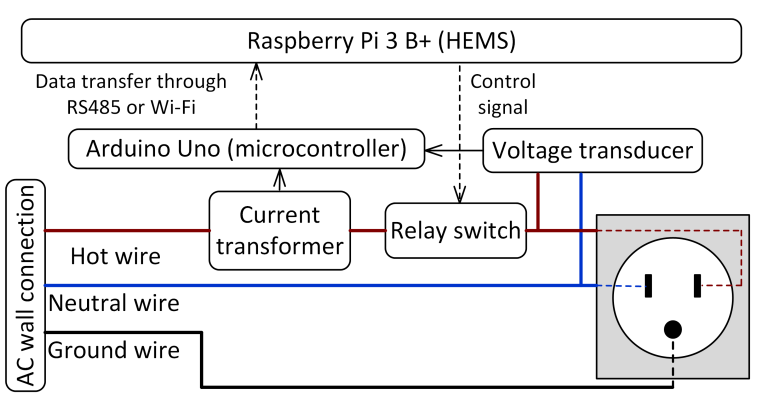

(a)

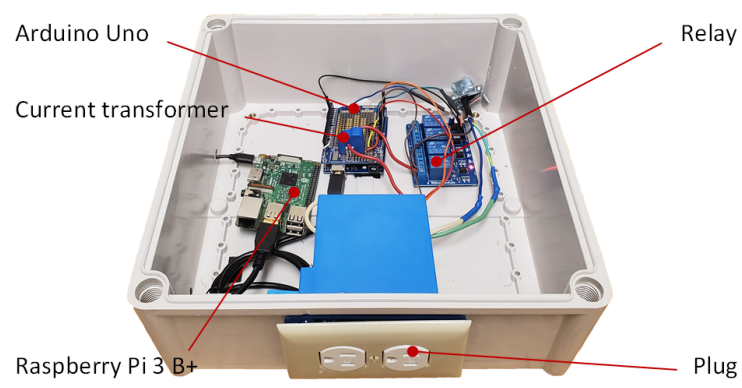

(b)

Figure 3. The developed smart plug prototype, (a) schematic representation illustrating data and power connections, (b) view under the hood (the voltage transducer is behind the blue plug and not shown).

load. The DC power supply has an uncontrolled rectifier and hence the input current is heavily distorted. The power factor is as low as 0.721 .

It is worth noting that both the currents drawn by the vacuum cleaner and the DC power supply have distorted waveforms including low-order harmonics. Such information may be employed by the HEMS for identifying the appliance type and ultimately tracking the energy consumption of individual devices from aggregated data.

\section{CONCLUSION}

This paper briefly reviews the latest developments in smart plug and circuit breaker technologies for efficient smart home management, focusing on efforts to improve energy usage in residential buildings by reducing the load from electronics, lighting and other home appliances, excluding electric water heaters and HVAC units. Such technologies may allow detailed consumer and utility studies for user behavioral patterns and electric power quality. The proposed smart plug, which has been developed and is described in the paper, has relatively low cost, provides detailed power quality assessments, including power factor and THD, and has the capability to be monitored and controlled by an HEMS, making it well suited for research projects.

\section{ACKNOWLEDGMENT}

The direct support of the University of Kentucky, Department of Electrical and Computer Engineering Undergraduate Research Fellowship program, of the TVA professorship endowment, and of the SPARK program is gratefully acknowledged. 
Table I

A COMPARISON OF THE DESIGNED SMART PLUG AND MICROCHIP POWER DEMONSTRATION BOARD, REFERRED TO AS MCP.

\begin{tabular}{|c|c|c|c|c|c|c|c|c|c|c|c|c|}
\hline Home appliances & \multicolumn{3}{|c|}{ Coffee maker } & \multicolumn{3}{|c|}{ Hair dryer } & \multicolumn{3}{|c|}{ Vacuum cleaner } & \multicolumn{3}{|c|}{ DC power supply } \\
\hline Measuring tool & MCP & Smart plug & Scope & MCP & Smart plug & Scope & MCP & Smart plug & Scope & MCP & Smart plug & Scope \\
\hline Current [Arms] & 7.47 & 7.81 & 7.82 & 13.34 & 13.96 & 14.00 & 9.65 & 10.14 & 10.20 & 2.12 & 2.23 & 2.23 \\
\hline Voltage [Vrms] & 118.5 & 121.2 & 121.0 & 115.5 & 117.1 & 118.0 & 117.8 & 119.8 & 120.0 & 121.8 & 123.6 & 123.0 \\
\hline Active power [W] & 887 & 945 & 940 & 1543 & 1617 & 1652 & 1112 & 1197 & 1220 & 195 & 201 & 198 \\
\hline Power factor & 1.000 & 0.999 & 0.994 & 1.000 & 0.989 & 0.999 & 0.980 & 0.984 & 0.997 & 0.750 & 0.727 & 0.721 \\
\hline THD [\%] & - & 3.61 & - & - & 4.65 & - & - & 19.6 & - & - & 90.58 & - \\
\hline
\end{tabular}
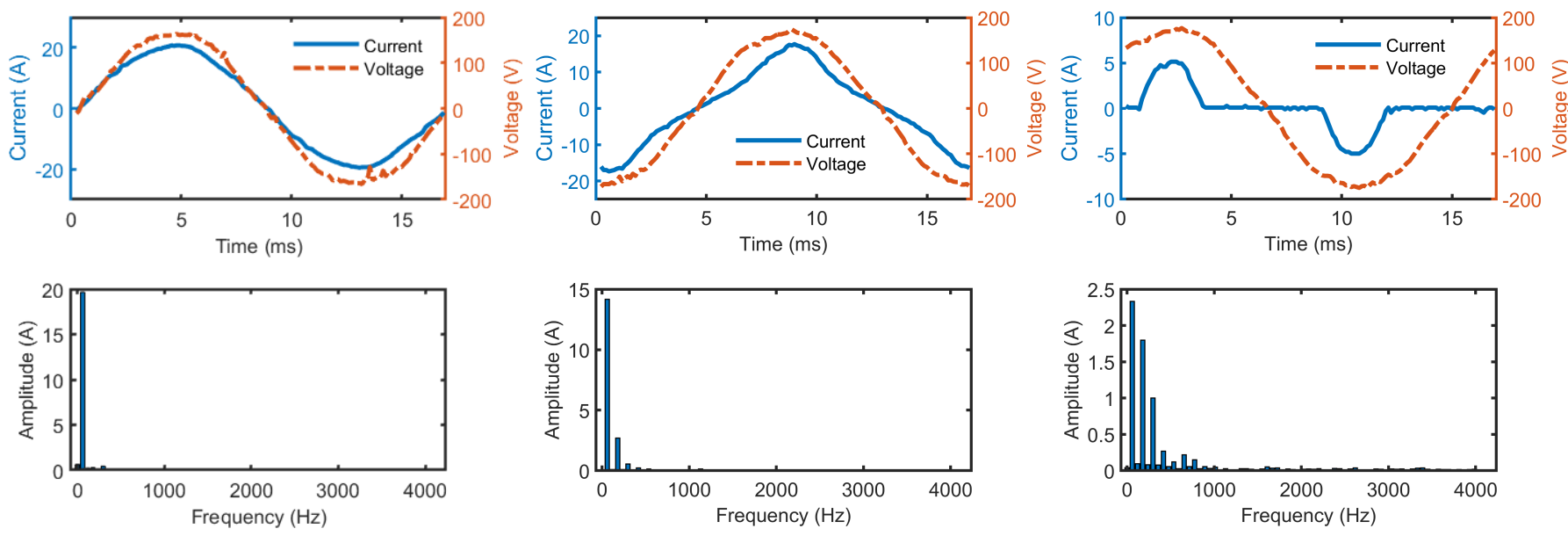

(a)

(b)

(c)

Figure 4. Waveforms and current spectrums for 3 typical home appliances under test, (a) hair dryer, (b) vacuum cleaner, (c) DC power supply.

\section{REFERENCES}

[1] S. van Dam, C. Bakker, and J. Buiter, "Do home energy management systems make sense? Assessing their overall lifecycle impact," Energy Policy, vol. 63, pp. 398 - 407, Dec. 2013.

[2] M. Roscia, M. Longo, and G. C. Lazaroiu, "Smart city by multi-agent systems," in International Conference on Renewable Energy Research and Applications (ICRERA), Oct. 2013, pp. 371-376.

[3] M. R. Tur and R. Bayindir, "Project surveys for determining and defining key performance indicators in the development of smart grids in energy systems," International Journal of Smart Grid, vol. 3, no. 2, pp. 103107, Jun. 2019.

[4] B. Zhou, W. Li, K. W. Chan, Y. Cao, Y. Kuang, and X. Liu, et al., "Smart home energy management systems: Concept, configurations, and scheduling strategies," Renewable and Sustainable Energy Reviews, vol. 61, pp. 30-40, Mar. 2016.

[5] U.S. Energy Information Administration, "2015 recs survey data." [Online]. Available: https://www.eia.gov/consumption/residential/data/2015/

[6] O. Elma, U. S. Selamogullari, M. Uzunoglu, and E. Ugur, "Carbon emission savings with a renewable energy supplied smart home operation," in International Conference on Renewable Energy Research and Applications (ICRERA), Oct. 2013, pp. 1129-1132.

[7] I. Papas, B. Estibals, C. Ecrepont, and C. Alonso, "Energy consumption optimization through dynamic simulations for an intelligent energy management of a BIPV building," in International Conference on Renewable Energy Research and Applications (ICRERA), Oct. 2018, pp. 853-857.

[8] P. Mtshali and F. Khubia, "A smart home energy management system using smart plugs," in Conference on Information Communications Technology and Society (ICTAS), Mar. 2019, pp. 1-5.

[9] V. Dolce, C. Jackson, S. Silvestri, D. Baker, and A. De Paola, "Socialbehavioral aware optimization of energy consumption in smart homes," in International Conference on Distributed Computing in Sensor Systems (DCOSS), Jun. 2018, pp. 163-172.

[10] W. Khamphanchai, A. Saha, K. Rathinavel, M. Kuzlu, M. Pipattanasomporn, and S. Rahman, et al., "Conceptual architecture of building energy management open source software (BEMOSS)," in IEEE PES Innovative Smart Grid Technologies, Europe, Oct. 2014, pp. 1-6.
[11] A. S. Al-sumaiti, M. H. Ahmed, and M. M. A. Salama, "Smart home activities: A literature review," Electric Power Components and Systems, vol. 42, no. 3-4, pp. 294-305, Feb. 2014.

[12] D. Arnone, V. Croce, G. Paternó, A. Rossi, S. Emma, and R. Miceli, et al., "Energy management of multi-carrier smart buildings for integrating local renewable energy systems," in IEEE International Conference on Renewable Energy Research and Applications (ICRERA), Nov. 2016, pp. 845-850.

[13] M. Pipattanasomporn, M. Kuzlu, and S. Rahman, "An algorithm for intelligent home energy management and demand response analysis," IEEE Transactions on Smart Grid, vol. 3, no. 4, pp. 2166-2173, Dec. 2012.

[14] X. Zhang, R. Adhikari, M. Pipattanasomporn, M. Kuzlu, and S. Rahman, "Deploying IoT devices to make buildings smart: Performance evaluation and deployment experience," in IEEE 3rd World Forum on Internet of Things (WF-IoT), Dec. 2016, pp. 530-535.

[15] S. Sagiroglu, R. Terzi, Y. Canbay, and I. Colak, "Big data issues in smart grid systems," in IEEE International Conference on Renewable Energy Research and Applications (ICRERA), Nov. 2016, pp. 1007-1012.

[16] Microchip Technology, "Energy metering ICs with active real power pulse output." [Online]. Available: http://ww1.microchip.com/downloads/en/DeviceDoc/22011B.pdf

[17] Analog Devices, "High performance, multiphase energy, and power quality monitoring IC ADE9000." [Online]. Available: https://www.analog.com/media/en/technical-documentation/datasheets/ADE9000.pdf

[18] Microchip Technology, "MCP3905A/06A evaluation board user's guide." [Online]. Available: http://ww1.microchip.com/downloads/en/ DeviceDoc/51567b.pdf

[19] Analog Devices, "ADE9000 technical reference manual UG1098." [Online]. Available: https://www.analog.com/media/en/technicaldocumentation/user-guides/ADE9000-UG-1098.pdf

[20] Sense. [Online]. Available: https://sense.com/technology

[21] Leviton. [Online]. Available: https://www.leviton.com/en/products/ residential/plugs-and-connectors/plugs

[22] Eaton Corporation. [Online]. Available: https://www.eaton.com/us/enus/markets/utilities.html

[23] Schneider Electric. [Online]. Available: https://www.schneiderelectric.com/en/work/products/product-launch/smart-panels/overview.jsp 